\title{
Research on Employment Difficulties and the Reasons of Typical Resource-Exhausted Cities in Heilongjiang Province during the Economic Transition
}

\author{
Weiwei Kong \\ School of Public Finance and Administration, Harbin University of Commerce, Harbin, China \\ kww119@sina.com
}

Keywords: typical resource-exhausted cities, economic transition, employment.

\begin{abstract}
The highly correlation between the development and resources incurs the serious problems of employment during the economic transition, such as greater re-employment population, lower elasticity of employment, greater unemployed workers in coal industry. These problems not only hinder the social stability, but also slow the economic transition and industries updating process. We hope to push forward the economic transition of resource-based cities and therefore solve the employment problems through the following measures: developing specific modern agriculture and modern service industry, encouraging and supporting entrepreneurships, implementing re-employment trainings, strengthening the public services systems for SMEs etc.
\end{abstract}

\section{Background}

According to the latest statistics from the State Council for 2013, there exists 239 resource-based cities in China, including 31 growing resource-based cities, 141 mature, and 67 exhausted. In the process of economic reform, resource-based cities face a series of development challenges. In December 2007, the State Council issued the Opinions on Promoting the Sustainable Development of Resource-Based Cities. The National Development and Reform Commission identified 44 resource-exhausted cities from March 2008 to March 2009, supporting them with capital, financial policy and financial transfer payment funds. In the year of 2011, the National Twelfth Five-Year Plan proposed to promote the transformation and development of resource-exhausted area. Issued in 2013, The State Council Plan for Sustainable Development of Resource-Based Cities (2013-2020) identified 239 resource-based cities in total with different types, including growing, mature, and exhausted. According to the Plan, there are 11 resource-based cities in Heilongjiang Province, 5 of which are mature-type, namely, Heihe, Daqing, Jixi, Mudanjiang, and Shangzhi, accounting for 3.55\% among the 141 cities of this type all over the country. And the other 6 are resource-exhausted cities, namely, Yichun Hegang, Shuangyashan, Qitaihe, Daxinganling, Wudalianchi, accounting for $8.96 \%$ among the 67 cities of this type all over the country. That is to say, the 11 resource-based cities in Heilongjiang province, accounts for $5.29 \%$ among the 208 cities of this two types all over the country. From the perspective of policy environment, it provides a rare opportunity for the resource-based cities in Heilongjiang to restructure and industrial upgrade. In the transition process, common problems exist in Heilongjiang province, including the depletion of resources, the decrease of industrial efficiency, the single structure, low levels of product structure, and substitute industries having not been formed. Therefore, the employment problems stand out, and lead to a sharp increase in pressure of social stability. We believe that in the grim situation of economic downturn, employment of Heilongjiang Province is becoming a more prominent issue in typical resource-based cities. We chose some typical resource-based cities with more obvious characteristics, such as the resource type, city features, and administrative ranking, as research objects in the employment problems. 


\section{Employment structure and difficulties in typical resource-exhausted cities in Heilongjiang province}

\subsection{Employment structure characteristics in typical resource-exhausted cities}

Employees in the secondary industry dominate in the employment structure. The proportion of secondary industry employment dominates in the resource-based cities of Heilongjiang province, which corresponds to its industrial structure. The unitary characteristic of resource industries determines the relative difficulty re-employment of the unemployed in the resource-based cities, therefore badly influence the society stability and economic transformation. The proportion of the workers in the secondary industry differs with the resource type cities (see Table 1).

Table 1. Employment Structure of Resource-based Cities in Heilongjiang Province in the Year of 2013 (Unit: ten thousand people)

\begin{tabular}{ccccccc}
\hline & \multicolumn{2}{c}{ Primary industries } & \multicolumn{2}{c}{ Secondary industries } & \multicolumn{2}{c}{ Tertiary industries } \\
\hline City & whole & municipal & whole & municipal & whole & municipal \\
& city & district & city & district & city & district \\
Daqing & 0.30 & 0.06 & 27.72 & 26.16 & 25.12 & 20.47 \\
Jixi & 1.28 & 0.06 & 9.71 & 8.71 & 8.01 & 4.83 \\
Hegang & 5.20 & 0.19 & 9.65 & 8.04 & 7.60 & 3.87 \\
Shuangyashan & 0.65 & 0.25 & 7.85 & 7.32 & 7.66 & 3.43 \\
Qitaihe & 0.46 & 0.31 & 8.13 & 7.73 & 4.09 & 3.17 \\
Yichun & 10.02 & 7.27 & 3.86 & 3.30 & 5.45 & 4.21 \\
\hline
\end{tabular}

Data resource: 2014 urban statistical yearbook of China

Laid-off workers are mainly from coal industry. State-owned enterprises face more difficult after the reform of state-owned enterprises, laid-off workers flows out, and most of the laid-off workers are mainly concentrated in the coal industry, such as the biggest four mining area, Hegang, Jixi, Shuangyashan and Qitaihe. With economic restructuring and industrial structure upgrading, these resources are drying up, which lead to a large number of workers becoming jobless in the late 1990s. Because of the narrow space of employment, unemployment shows the characteristics in the long-term.

In the year of 2009, the government holds $88 \%$ of all the large-capacity industrial added value (35\% more than average level in our country), which leads to prominent problem of unemployment for workers from State-owned enterprises. In the meanwhile, the number of laid-off workers is 0.199 million, accounting for $22 \%$ of all state-owned enterprise workers. From the distribution, unemployed mainly concentrated in the coal industry. One reason is that part of the corporations restructure, another reason is the impact of the financial crisis effects on the employment situation. Part of the less competitive corporations bankruptcies, closures, layoffs and cutbacks. Furthermore, the overwhelmed Dragon Coal Group closed four mines and carry out some policy to accommodate surplus staff. more than three thousand workers in Qixing coal mine in Shuangyashan will be facing with various forms of "laid off" ${ }^{\text {[3] }}$.

\subsection{Employment difficulties in economic transformation in resource-based cities Heilongjiang province}

The number of re-employment is more than normal in transformation. There are three main reasons of unemployed above normal in resource-based cities in Heilongjiang province. Firstly, resource depletion or reorganization of assets result in cutting. Secondly, resource-based enterprises leads to atrophy depression affiliates and the unemployed from other enterprises are lack of competence. Thirdly, lack of new urban economic growth causes new workers unemployed. Thus, the transition leads to increased number of re-employment. 


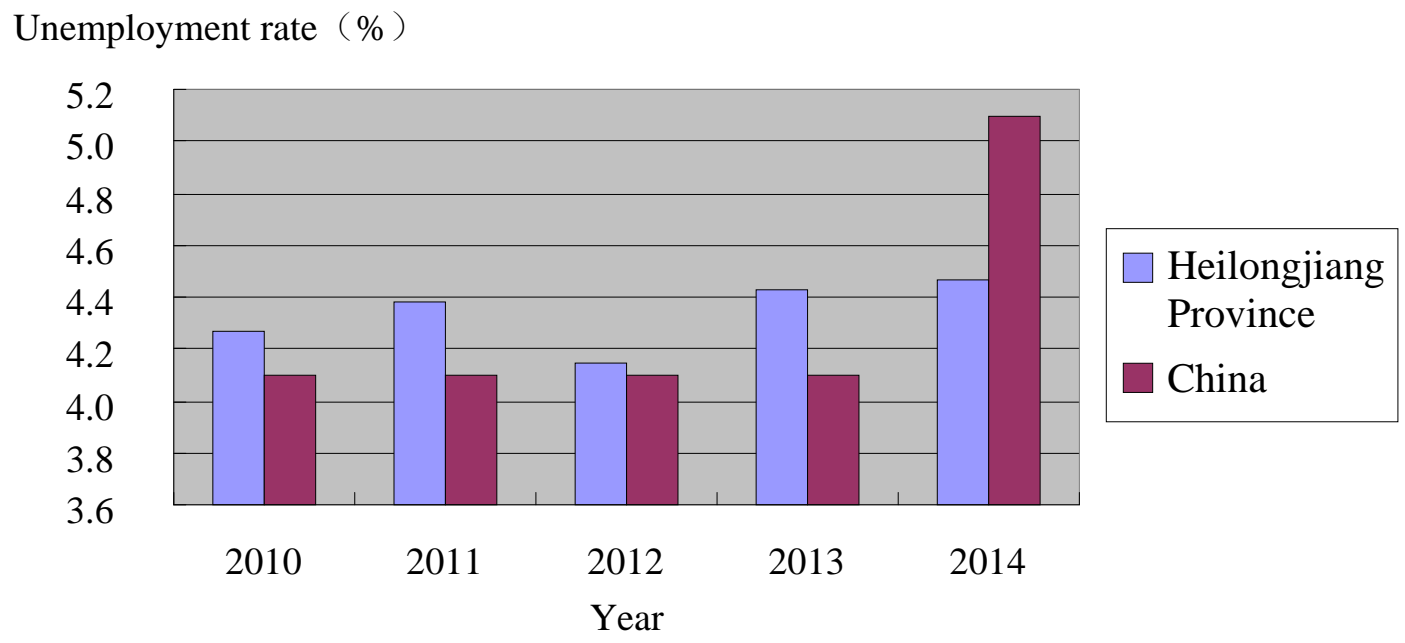

Figure 1. Urban Registered Unemployment Rate Comparison

Data resource: National Bureau of Statistics and the Ministry of Human Resources and Social Statistics

It can clearly be seen from Figure 1 that, the urban unemployment rate of Heilongjiang province is higher than the national average unemployment rate. It is generally higher than the national average unemployment rate at 0.3 percentage points in the past five years. For example, in 2010 the country registered urban unemployment rate was $4.0 \%$, Heilongjiang $4.3 \%$, higher than the national average. Unemployment is particularly prominent in resource-based cities. And the unemployment rate in some towns in the early transition has reached more than $10 \%$, far more than the cordon $7 \%$. By the end of 2005, four coal cities (Jixi, Hegang, Shuangyashan and Qitaihe) reached 11 million laid-off workers, re-employment rate was only $11.4 \%$ at the same time.

From the definition of employment elasticity, we can get the elasticity of Heilongjiang Province in 2000-2010. Table 2 is calculated by statistical yearbook of Heilongjiang Province.

Table 2. Employment Elasticity for the Three Major Industries in Heilongjiang Province in Year of 2000-2010

\begin{tabular}{ccccc}
\hline Year & $\begin{array}{c}\text { Overall } \\
\text { elasticity }\end{array}$ & $\begin{array}{c}\text { Primary } \\
\text { industries }\end{array}$ & $\begin{array}{c}\text { Secondary } \\
\text { industries }\end{array}$ & $\begin{array}{c}\text { Tertiary } \\
\text { industries }\end{array}$ \\
\hline 2000 & -0.06 & 0.01 & -0.03 & -0.01 \\
2001 & 0.07 & 0.04 & -0.02 & 0.25 \\
2002 & 0.07 & 0.24 & -0.62 & 0.27 \\
2003 & 0.41 & -0.18 & 1.21 & 1.24 \\
2004 & 0.36 & -0.16 & 1.05 & 0.79 \\
2005 & 0.35 & -0.08 & 0.26 & 1.08 \\
2006 & 0.17 & 0.02 & 0.18 & 0.36 \\
2007 & 0.20 & -0.08 & 0.45 & 0.42 \\
2008 & 0.12 & 0.05 & -0.22 & 0.40 \\
2009 & 0.41 & 0.16 & -0.06 & 0.14 \\
2010 & 0.14 & -0.13 & -0.13 & 0.6 \\
\hline
\end{tabular}

Data resource: Statistical Yearbook of Heilongjiang Province.

From Table 2, we can see that the employment elasticity of the major three industry show a low level before the year of 2003. In the year of 2003, the Secondary and the Tertiary industry both increase greatly, which improve the elasticity of the employment on the whole. That is related to the strategy of Rejuvenation of Northeast Old Industrial Base. In the meanwhile, the whole elasticity of employment decreases and at a low level on the whole, which phenomenon should be given attention. 


\section{Reasons for employment problems in typical resource-exhausted cities in Heilongjiang province}

\subsection{Anaemic and unstable economy growth}

Many resource-based cities in Heilongjiang, especially for the coal cities, were first set up by the mines, which have a great influence on the economic growth. Once the resource industry suffers loss, the city would come across damage, develop slowly, and even cause social problems. Though some new industry comes out in some cities, there is no effective connection between the old and the new, which lead to no competitiveness for the new industry. Furthermore, there is no enough time to transform for some cities which have no alternative industries. Little effect achieved in new industry, the tradition industry makes up larger proportions than the new, which has a small scale and struggles in transformation. According to the latest GDP growth rate statistics, the economy grows steadily from 2004 to 2012, however downturns evidently.

\subsection{High proportion of capital-intensive industries}

Compared to general city, the secondary industry proportion is larger, and the tertiary industry proportion is smaller in the view of industrial structure in the resource-based city in Heilongjiang Province. For example, in the year of 2007, the secondary industry proportion in Daqing is $85 \%{ }^{[5]}$ In recent years, industrial structure in those cities changes continually. The secondary industry goes up and the tertiary industry goes down in such as Hegang, Shuangyashan and so on. In the view of industrial internal structure, the proportion of heavy industry is very high, and goes higher and higher, while, the proportion of light industry is low, and goes lower and lower. It has a characteristic of high capital intensity for the secondary industry, especially for the heavy industry in the secondary industry. At the same time, few employees will be needed if the capital was invested in those industry. The proportion of the secondary and heavy industry is rising all the time and will do harm to the employment in resource-based cities. From this point of view, Employment difficulty in some resource-based cities mainly caused by the industrial structure, and industry with high capital intensity goes up high, while tertiary industry with high labor intensity goes down continuously.

\section{Acknowledgement}

This research was financially supported by the National Social Science Fund of China (Grant No. 14BJY032).

\section{References}

[1] Li Dongyang. Research on the Economic Transformation of the Resourse-exhausted City: the Case Study of Liaoyuan City. Jilin University, 2009(3).

[2] Li Min. A Study on Issues of Employment in China. [J]. Journal of Huazhong University of Science and Technology, 2009(06).

[3] Li Chunlian, Long Coal Group closed four mines, workers are laid off: Coal city experienced resource crises. Securities Daily.2014.07.17.

[4] Yao Jing. Survey on professional in coal deep-processing enterprises in Qitaihe.[J].Coal Processing \& Comprehensive Utilization, 2011.

[5] Hu Shuge. Research on employment $f$ lexible of laid off workers in resourde-exhausted cities in Heilongjiang Province. [J]. The journel of Harbin committee school of the CCP.2009 (5). 